\title{
PRESENÇA DO ASSOCIATIVISMO DAS UNIVERSIDADES ESTADUAIS PAULISTAS NA HISTÓRIA DO SINDICALISMO EDUCACIONAL LATINOAMERICANO
}

Silvana Fernandes LOPES ${ }^{1}$

Carlos BAUER ${ }^{2}$

RESUMO: Este artigo insere-se em uma investigação mais ampla, cujo objetivo é discutir a história e os embates políticos do sindicalismo docente universitário na América Latina. Nesse sentido, este trabalho privilegia alguns aspectos da organização sindical docente no Brasil e toma como foco as entidades vinculadas às universidades estaduais paulistas, procurando compreender o papel desses sindicatos e associações em uma perspectiva histórico-social. Propõe-se, também, analisar os embates políticos e a atuação junto aos educadores, tendo como recorte os anos 1990-2010, período marcado pelas políticas governamentais voltadas para as reformas do Estado, em geral, e para as universitárias, em particular. Coloca-se, portanto, no campo de uma história social crítica da educação, procurando contribuir com a produção de um conhecimento que traga à tona as ações, as lutas e os questionamentos dos sindicalistas universitários aos modelos educacionais vigentes, estimulando, assim, as reflexões que tornem possível a convergência de seus propósitos políticos e sociais.

PALAVRAS-CHAVE: Associativismo. Sindicalismo docente. Trabalhadores em educação.

\section{INTRODUÇÃO}

Os últimos decênios do século $\mathrm{XX}$ registraram intensas modificações econômicas, políticas e sociais na maioria dos países latino-americanos, com destaque para o processo de redemocratização experimentado por diferentes nações dessa região. Nesse contexto, muitas vezes marcado por conflitos e por mobilizações sociais, também se verificou a disposição das elites políticas em promover o que se convencionou chamar de reforma do Estado. Muito embora esse intento não possa ser caracterizado

\footnotetext{
${ }^{1}$ Doutora em Educação. UNICAMP - Universidade Estadual de Campinas. Professora do Departamento de Educação da UNESP - Universidade Estadual Paulista Júlio de Mesquita Filho, Campus São José do Rio Preto. Professora do Programa de Pós-Graduação em Educação. UNESP - Universidade Estadual Júlio de Mesquita Filho. Marília - SP - Brasil. 17525-900 - silvanaflopes@ gmail.com.

${ }^{2}$ Doutor em História. USP - Universidade de São Paulo. Pós-doutoramento, em Educação. UNICAMP Universidade Estadual de Campinas. Professor do Programa de Pós-Graduação em Educação - PPGE. UNINOVE - Universidade Nove de Julho. São Paulo - SP - Brasil. 05010000 carlosbauer@pesquisador.cnpq.br.
} 
como regra, com características homogêneas em cada um dos países, alguns dos seus aspectos mais relevantes são os mesmos e os atingiu indistintamente.

As condições estruturais de cada país influenciaram na dinâmica de aceitação, de repulsa e de condicionamento do alcance dessas reformas. Esse conjunto de propostas de reestruturação da economia trouxe uma série de mudanças que tiveram implicações significativas nas relações culturais, de trabalho e de poder entre as distintas classes sociais e suas representações políticas e dirigentes de ações coletivas.

Relacionado diretamente com esses processos de transformações econômicas, políticas e sociais, a problemática educacional foi ganhando destaque nos discursos dos governantes latino-americanos, os quais passaram a assumir compromissos de investirem mais recursos no setor, de universalizar o acesso à educação básica e de melhorar a qualidade e a abrangência social dos seus sistemas educativos.

Em diferentes países da América Latina, foram realizadas mudanças significativas no sistema educativo, preconizando sempre como objetivo a melhoria da qualidade da educação. Nessa direção, a descentralização, o fortalecimento do poder local e a promoção da autonomia foram pontos comuns que estiveram presentes nas plataformas das reformas recomendadas na maioria dos países.

No entanto, a efetivação dessas propostas trouxe mudanças que afetaram direta e profundamente os docentes e as organizações sindicais dispostas a representá-los. Estas, invariavelmente, opuseram-se às reformas e constituíram-se em um dos obstáculos para a sua concretização.

Em linhas gerais, revela-se importante investigar a história da resistência e dos conflitos protagonizados entre os sindicatos docentes universitários e os governos nacionais dos países latino-americanos, uma vez que os processos de reforma estiveram centrados em quatro questões fundamentais: 1) as condições de trabalho, os salários e a valorização da profissão docente; 2) a organização e a gestão do sistema educativo local, regional e nacional; 3) o planejamento das reformas com a garantia de diálogo e espaço de participação das organizações docentes nos fóruns de decisão política; e 4) a avaliação docente e discente.

Além disso, como parte integrante do movimento mais geral dos trabalhadores, o sindicalismo docente latino-americano tem sido o porta-voz de uma visão de sociedade que se opõe ao liberalismo econômico e às condições que este impõe aos que vivem do trabalho. 
São poucos os estudos que buscam construir uma história social e crítica do sindicalismo universitário latino-americano, tendo como abrangência os seus pontos de confluência e as suas tensões; e que analisem as suas experiências políticas, suas lutas corporativas, suas práticas culturais, seus questionamentos aos poderes governamentais e às agências internacionais, e, ainda, as possibilidades de atuação contra-hegemônica nesta etapa histórica da mundialização do capital.

Nesse sentido, é importante pensar a construção da história da educação latinoamericana por meio das vozes dos seus personagens coletivos e por intermédio de jornais, de livros, de panfletos sindicais e de outras manifestações da cultura material que foram e são produzidos com o objetivo de combater a ordem política, econômica e social estabelecida.

Trata-se, portanto, de trazer para o campo da pesquisa na área educacional estudos que tenham como preocupação as experiências e formas de organização política e sindical dos educadores, procurando compreendê-los dentro de um contexto de expressão de suas concepções de mundo e de crítica social, em um terreno arduamente construído e de constante tensão social.

\section{Brevíssima revisão da literatura sobre o associativismo e sindicalismo dos trabalhadores em educação}

Um rápido balanço da bibliografia sobre o sindicalismo docente na América Latina confirma a existência de dois grandes processos que chamaram a atenção dos estudiosos do assunto. O primeiro foram as grandes mobilizações docentes da década de 1980. Tais acontecimentos foram verificados especialmente no México e no Brasil, onde têm início greves bastante radicais a partir de 1978 e 1979, respectivamente. Também foram registrados movimentos grevistas no Peru, na Argentina e no Chile, nos quais a mobilização sindical foi retomada, e, no período compreendido entre 1968 e 1975, vigorosas experiências sindicais foram levadas adiante. Esse processo de agitação dos sindicatos de professores na região pode ser explicado pela longa recessão econômica, que debilitou as contas físcais e, por essa via, a remuneração dos professores; pela continuidade do processo de expansão do sistema educacional, conseguido, em parte, por meio da redução salarial dos trabalhadores do sistema; pelas altas taxas de inflação, que empurraram os trabalhadores para conflitos grevistas em 
busca da manutenção do poder aquisitivo; e pelos processos de democratização política, os quais favoreceram a expressão do descontentamento generalizado e a politização dos movimentos. Entre os temas de pesquisa apareceram a própria mobilização (mecanismos de participação, métodos de luta, greves e democracia sindical), a identificação dos docentes como "trabalhadores em educação" e a história protossindical ou sindical da categoria.

O segundo processo que interessou aos pesquisadores foi a posição dos sindicatos diante da agenda de reformas instaladas já no início da década de 1990. Em que pesem as diferenças entre os países, a estabilização econômica e a hegemonia ideológica e política do neoliberalismo possibilitaram instalar uma série de reformas que produziu tensões com as organizações docentes. Os temas mais controvertidos foram principalmente os seguintes: a desconcentração do emprego, a flexibilização trabalhista, a participação da comunidade na administração dos centros escolares e as propostas de avaliação do desempenho docente. Essas reformas foram realizadas contra os sindicatos e as investigações refletiram essa situação. Com efeito, quer pela via de posições de força (no México, por exemplo) quer pelo seu papel de deslegitimação das reformas educacionais (caso da Argentina, da Bolívia, do Brasil etc.), os sindicatos de professores foram os grandes agentes da moderação do ímpeto reformista dos anos 1990.

No Brasil, existe uma importante produção sobre sindicalismo docente, embora tenha pouca visibilidade internacional. Essa produção é realizada basicamente nos programas de pós-graduação em Educação, mas existem alguns trabalhos que têm sido desenvolvidos fora do âmbito acadêmico e se agrupam em estudos de caso sobre sindicatos estaduais. Há algumas poucas pesquisas que comparam sindicatos do mesmo estado, outras poucas nacionais ou interestaduais, e também alguns trabalhos desenvolvidos nos programas de pós-graduação em História e em Sociologia. As temáticas privilegiadas são a mobilização e a desmobilização da categoria, a identidade dos professores e a ação sindical frente às reformas educacionais. No que se refere aos estudos sobre o sindicalismo docente na América Latina e no Brasil, propriamente ditos, podemos destacar Dal Rosso (2011), Gindin (2009), Gentili (2004), Vianna (1999), Almeida e Ferreira Júnior (2015), Gouveia e Ferraz (2013), que são chamados a colaborar com a construção dos nossos estudos.

Nossas discussões estão inseridas no campo da construção de um pensamento contra-hegemônico e remontam aos debates que são próprios do referencial teórico que 
se convencionou chamar de marxismo. O materialismo histórico dialético é a base de nossas análises e reflexões sobre o desenvolvimento e os protagonistas sociais do sindicalismo docente universitário na América Latina. Essa perspectiva de produção do conhecimento historiográfico revelou amplos laços sociais e culturais pertinentes ao mundo do trabalho, concedeu o papel de protagonistas da história também para as classes inferiores e para os personagens invisíveis da "história oficial".

O presente trabalho está inserido nessa investigação mais ampla, que procura discutir a história e os embates políticos do sindicalismo docente universitário na América Latina.

Dentro desse quadro geral, este trabalho privilegia alguns aspectos da organização sindical docente no Brasil, no período compreendido entre 1990 e 2010. Para tal, tomamos como foco o Sindicato Nacional dos Docentes do Ensino Superior (ANDES), a Associação dos Docentes da Universidade Estadual Paulista (ADUNESP), a Associação de Docentes da Universidade Estadual de Campinas (ADUNICAMP) e a Associação dos Docentes da Universidade de São Paulo (ADUSP).

Nesse sentido, procuramos compreender o papel desses sindicatos e associações em uma perspectiva histórico-social e, por meio desse processo, constatar e analisar os embates políticos, sua atuação junto aos educadores, tendo como recorte os anos entre 1990 e 2010, período marcado pelas políticas governamentais voltadas para as reformas do Estado, em geral, e, em particular, para as universitárias.

\section{Sindicato Nacional dos Docentes do Ensino Superior (ANDES)}

O Sindicato Nacional dos Docentes do Ensino Superior - entidade representativa nacional dos docentes das instituições públicas do ensino superior - teve e tem um papel destacado em lutas, tanto em questões sindicais imediatas, tais como as salariais e as que dizem respeito às condições de trabalho nas instituições, quanto na incorporação de bandeiras mais gerais e políticas, tais como a resistência às políticas neoliberais e a proposição de um projeto contra-hegemônico de sociedade.

Desde a sua fundação, em 1981, a entidade nacional tem como objetivo atuar na vinculação entre o trabalho acadêmico e profissional interno às universidades e a realidade social brasileira, buscando a não dissociação entre ambos. Essa postura repercute em seu posicionamento, ao incorporar uma ampla pauta de questões com um forte recorte classista, conferindo-lhe uma marca registrada e, assim, diferenciando-se 
das demais entidades representativas de docentes da iniciativa privada - os Sindicatos de Professores Regionalizados (Sinpro's).

De acordo com o ANDES ([19--]), a sua atuação no movimento docente “constituiu-se na relação permanente com as experiências de outros trabalhadores que lutam pelo reconhecimento de direitos sociais para todos os brasileiros".

Com essa determinação, o sindicato nacional tomou uma posição de combate à ofensiva neoliberal que se efetivou a partir dos governos Fernando Henrique Cardoso, sendo um importante instrumento de resistência por parte dos docentes e dos trabalhadores de sua base social, embora nem sempre alcançando resultados concretos. O seu peso dentro do movimento sindical brasileiro é destacado e suas seções sindicais (entre elas, as seções paulistas) visam atuar de forma combativa em diversas ocasiões, como nas greves realizadas no período. Essa caracterização não sofreu grandes mudanças com a ascensão dos governos de Frente Popular de Lula e de Dilma, como pudemos observar durante as lutas contra as reformas previdenciária, sindical e trabalhista que se configuraram no período. A sua atuação, em uma nova conjuntura política e sindical no Brasil, fez com que a entidade rompesse com a Central Única dos Trabalhadores (CUT), em 2005, e que, em seu $26^{\circ}$ Congresso na Paraíba, em 2007, fosse deliberada a sua filiação à Coordenação Nacional de Lutas - atual CSPCONLUTAS.

O estado de São Paulo, considerado o ente federativo mais rico e desenvolvido do país, não esteve à parte desse processo. As universidades estaduais paulistas (leia-se USP, UNESP e UNICAMP) também sofreram e sofrem intervenções que buscam adequá-las ao projeto neoliberal. Como apontado acima, suas entidades representativas - de cunho sindical ou associativista - cumprem um papel, mesmo que precário, nas lutas e na resistência, articulando professores e trabalhadores nos embates isolados e/ou amplos que se desenvolvem dentro e fora das universidades.

Analisar como essas entidades caracterizam-se histórica e socialmente nos permite compreender como se desenvolvem os processos de avanço e de recuo da ação e do "protagonismo" desses sujeitos sociais frente a esses desafios. Ao investigarmos o caso específico dessas entidades, nos é possível compreender o fenômeno em um contexto mais geral, sem negar, no entanto, as características próprias de outras regiões do país. Dessa forma, apresentaremos, a seguir, um breve levantamento das características históricas das entidades representativas existentes no interior do ensino superior público paulista. 


\section{As entidades vinculadas às universidades estaduais paulistas}

\section{Associação dos Docentes da Universidade Estadual Paulista (ADUNESP)}

Uma das características das mobilizações existentes nas universidades brasileiras é o fracionamento das entidades que se apresentam como representantes dos sujeitos sociais atuantes nesses ambientes. Como podemos verificar em outros casos, na Universidade Estadual Paulista "Júlio de Mesquita Filho" (UNESP), os professores e pesquisadores se organizaram separadamente dos demais trabalhadores da instituição, compondo uma entidade exclusiva para o seu segmento.

A UNESP foi criada em 1976, a partir da incorporação dos Institutos Isolados de Ensino Superior do Estado de São Paulo, e teve como uma das suas principais medidas a não duplicação de recursos financeiros. Por essa razão, muitos cursos foram fechados e os professores, deslocados para outros campi. É nesse contexto que a Associação dos Docentes da UNESP (ADUNESP) foi fundada, também em 1976, motivada pelas lutas contra o fechamento dos cursos e contra a transferência dos docentes.

A entidade posicionou-se no campo da luta democrática e no combate ao regime civil-militar instaurado no país em 1964. Nas grandes mobilizações características dos anos 1980, a ADUNESP buscou organizar sua base social, tanto do ponto de vista das bandeiras sindicais específicas quanto das lutas políticas em nível nacional.

Os anos 1990 foram marcados pelas lutas e resistências à implantação das políticas neoliberais, ao processo de privatização, à precarização das condições de trabalho dos docentes e ao sucateamento da instituição como um todo. O combate se deu no campo sindical e político, fazendo oposição não somente aos governos federal e estadual de então, mas também aos reitores que ocuparam o cargo ao longo desses anos.

Mais recentemente, as suas características a aproximam da definição de sindicato, apesar de não ser assim designada. Reivindica-se como seção sindical do Sindicato Nacional dos Docentes do Ensino Superior - ANDES-SN - e suas diretorias têm adotado uma postura crítica e combativa frente aos governos dos presidentes Lula e Dilma, apontando-os como continuadores da implementação das políticas neoliberais no Brasil e, mais especificamente, no ensino superior público nacional.

\section{Associação dos Docentes da Universidade de Campinas (ADUNICAMP)}


Como observado na ADUNESP, a Associação dos Docentes da Universidade Estadual de Campinas (ADUNICAMP) também busca organizar o conjunto dos professores e pesquisadores da UNICAMP, mas sem representar outros segmentos de trabalhadores existentes no interior da universidade.

Criada em 1977, a ADUNICAMP também nasceu em meio ao contexto das lutas contra a ditadura civil-militar. Em sua fundação, realizada em uma assembleia, que contou com a participação de 370 professores, a entidade assumiu a tarefa de:

[...] atuar como um sindicato, lutando pelos direitos trabalhistas dos professores, e também como uma associação de trabalhadores preocupada com a democracia, empenhada em unir-se a outras entidades semelhantes, apoiando-as. Ao mesmo tempo, deveria dar sua contribuição à Universidade pública brasileira - com o propósito de identificar qual o lugar dessa instituição em um país com as particularidades do Brasil - e à própria Unicamp, que carecia de mecanismos de decisão transparentes e abertos (ADUNICAMP, 1977).

Já em 1978, a entidade organizou sua primeira greve de professores na instituição e, no ano seguinte, participou do amplo movimento do funcionalismo paulista, em conjunto com outras categorias de servidores públicos e trabalhadores em educação. A partir de então, a ligação com entidades de docentes de outras universidades públicas paulistas permitiu o desenvolvimento de laços que culminaram na formação do Fórum das Seis (entidade que inicialmente congregava as associações de docentes e de servidores técnico-administrativos das três universidades públicas paulistas e que atualmente congrega, ainda, os Diretórios Centrais de Estudantes (DCEs) da UNICAMP e da USP, e o sindicato dos trabalhadores do Centro Paula Souza (ADUNICAMP, 1977).

Um dos destaques que se faz em relação aos últimos anos, além das greves marcantes desse período, foi à transformação estatutária e jurídica da ADUNICAMP em um sindicato e em seção sindical do ANDES-SN. Esse processo é apontado como fruto de um amplo debate com a base da categoria e que permitiu o avanço da entidade enquanto instrumento de luta dos professores da universidade.

\section{Associação dos Docentes da Universidade de São Paulo (ADUSP)}


Não obstante fazer parte do mesmo contexto das demais universidades e entidades, a Associação dos Docentes da Universidade de São Paulo (ADUSP) surgiu como alternativa de atuação e representação à Associação dos Auxiliares de Ensino, criada em 1956, para defender os interesses dos professores não catedráticos. Essa entidade foi considerada ineficaz e pouco atuante durante a ditadura civil-militar. Além disso, o grande impulso para o surgimento das mobilizações na segunda metade da década de 1970 foi o assassinato do jornalista e também professor da USP Vladimir Herzog, nas dependências do DOI-CODI de São Paulo.

Nesse contexto, os docentes e pesquisadores da universidade perceberam a " $[\ldots]$ necessidade da criação de uma entidade que os representasse, que promovesse a integração docente e que encaminhasse as reivindicações da categoria.” (ADUSP, [19-]). Como parte dessa luta, a entidade participou ativamente das mobilizações pela redemocratização do país entre o fim da década de 1970 e o início dos anos 1980, além de atuar como instrumento de ação, reivindicando conquistas salariais, melhores condições de trabalho e mais verbas para a educação, buscando se associar aos demais movimentos sociais existentes dentro e fora do ambiente universitário.

Os anos 1990 foram marcados por mobilizações contra as políticas neoliberais implantadas pelos governos federal e estadual. Essas lutas tiveram continuidade nos últimos 20 anos, quando a ADUSP se posicionou contrária às reformas previdenciária, sindical e trabalhista, que começaram a ser discutidas e implementadas nos governos Fernando Henrique Cardoso e continuadas nos governos Lula e Dilma. Destaca-se a sua atuação, junto com as demais entidades, na construção do Sindicato Nacional dos Docentes do Ensino Superior - ANDES-SN - tornando-se, em 1990, sua seção sindical no interior da USP. Além disso, a questão democrática é, muitas vezes, citada e reivindicada, como na citação abaixo:

Termino evocando a experiência recente da Associação dos Docentes da Universidade de São Paulo (ADUSP), em cujos quadros milito. Foi ela que, pela primeira vez, criou nos seus conselhos e assembléias um ambiente onde os docentes de todas as categorias se encontraram, discutiram, concordaram, divergiram, decidiram em pé de igualdade, coisa inexistente na vida universitária reconhecida pelos regulamentos internos. Com isso, ela deu expressão ao que é realidade atual do ensino e pesquisa, feitos igualmente por docentes de todas as categorias, e não por titulares aos quais se reconhece lugar privilegiado nas deliberações. [...] Sua grande vitória foi a fundação de um modo novo de conceber a atividade docente, seus deveres, sua 
capacidade de ação, seu futuro regenerador ao lado dos colegas de outros níveis, dos funcionários, dos alunos. (CÂNDIDO, 1979).

Apesar de representar apenas os docentes da universidade, a ADUSP busca uma aproximação estreita com outras entidades, como o Sindicato dos Trabalhadores da USP (SINTUSP), com o princípio da necessidade da união da classe trabalhadora para fazer frente à ofensiva do capital e dos governos burgueses.

Como já apontado ao longo deste trabalho, apesar do grau de organização dessas entidades, há muitas dificuldades a serem enfrentadas. É notório que a participação dos docentes nas suas entidades está cada vez mais fraca. No que se refere à educação superior, especificamente, fica evidente a mercantilização do trabalho docente, tornando a gestão das universidades cada vez mais empresarial. As mudanças no trabalho docente, a partir de 1990, levaram à intensificação e extensão temporal desse trabalho. Na maior parte das vezes, o aumento das exigências fez com que os docentes, ao invés de se organizarem coletivamente para lutar contra a exploração, se tornassem cada vez mais produtivistas, competitivos e empreendedores.

Essa mudança, que Gentili (2001, p.100) denominou de “[...] reconversão intelectual do campo acadêmico”, “[...] conduz à redefinição da própria função social das instituições de educação superior e do papel político exercido pelos profissionais que nelas atuam, configurando uma nova geopolítica dos saberes hegemônicos e de sua institucionalização universitária.” (MANCEBO, 2011, p.79). Essas questões colaboram para a escassez da crítica e, principalmente, para o esmorecimento da prática políticosindical.

A questão das mudanças ocorridas na cultura acadêmica acarretam efeitos sobre as lutas dos professores. Da década de 1990 para cá, as representações, as motivações e as normas éticas dos docentes foram canalizadas para o individualismo no enfrentamento dos problemas causados pelas condições de trabalho.

Trata-se de uma nova cultura acadêmica que ocorre no próprio tecido universitário e que é nada desprezível, porque miúda, caucionada pelo discurso do mérito, mas pretensiosa nas intenções, na medida em que procura agir desmontando os direitos sociais que pudessem ser ordenados como compromisso social coletivo e as iniciativas de enfrentamento, de participação política e sindical. (MANCEBO, 2011, p.85). 
Nesse sentido, as entidades sindicais enfrentam, entre outros problemas, dificuldades na construção de pautas comuns de reivindicação, base através da qual poderiam canalizar o seu potencial de pressão e de mobilização.

Essas questões, como aponta Sader (2009), são as maiores conquistas do neoliberalismo.

\section{Considerações finais}

Após analisar o reduzido número de pesquisas, o escasso estímulo a investigações sobre associativismo e sindicalismo dos trabalhadores em educação, o enorme campo aberto para estudos em âmbito nacional e internacional, a necessidade de estimular pesquisas em âmbito nacional e em cooperação internacional, resolvemos nos dedicar aos estudos sobre essa temática, com a ambição de transformar a fragmentação teórica, disciplinar e temática dos estudos em terreno fértil sobre o qual se possa aprofundar e potencializar as investigações em andamento e fomentar novas perspectivas no campo, além de promover e ampliar pesquisas sobre as origens, o desenvolvimento e a história de associações e sindicatos em educação.

Por sua vez, a periodização e a temática estão associadas a termos verificado no Brasil, a exemplo do que ocorre em toda a América Latina e no mundo, o avanço e a consolidação de políticas neoliberais, que, em palavras sucintas e parciais, transfere os recursos do Estado - anteriormente alocados em serviços públicos característicos do Estado do Bem-Estar Social - para a iniciativa privada, consequência da nova etapa histórica do capitalismo.

A transferência desses recursos do fundo público para os interesses de grandes corporações privadas tem produzido resultados preocupantes no ensino superior latinoamericano. Setor antes foco de abundantes investimentos até meados da década de 1970, a partir de então se tornou alvo dessas políticas neoliberais, tanto no plano econômico/financeiro como ideológico. A busca por eficiência, o produtivismo, a otimização dos gastos e a necessidade de retornos de resultados que apresentem uma balança favorável para os interesses do capital se tornaram a tônica nesses últimos 20 anos.

No entanto, como todo processo dialético existente, esse fenômeno não se caracterizou como uniforme, linear, progressivo e tranquilo. Muitos de seus objetivos traçados não foram completamente alcançados como o esperado. Contradições se 
gestaram e se desenvolveram no interior dessa situação. Vozes, mesmo que minoritárias, se levantaram e articularam ações coletivas que promoveram certa resistência à aplicação dessas políticas no interior das instituições de ensino superior, como também críticas - no plano ideológico - desse mesmo fenômeno em praticamente toda a América Latina. Alguns dos sujeitos sociais que se destacaram nessa resistência foram as entidades representativas dos professores e trabalhadores das universidades, que, por suas características e por seus históricos, encabeçaram, em determinados momentos, juntamente com outras entidades, como a dos estudantes, a luta em defesa da educação pública, gratuita e de qualidade no ensino superior.

Os estudos preocupados com a história dos trabalhadores e os seus esforços organizativos políticos, associativistas e sindicais não são recentes, mas essa longevidade não é acompanhada de uma produção substancial, constante e crescente de pesquisas que tem privilegiado essa temática nos programas de pós-graduação e centros de estudos espalhados pelas universidades nacionais e estrangeiras.

Este trabalho pretende, portanto, contribuir não apenas com a produção de um conhecimento que possa trazer à tona as ações, as lutas e os questionamentos dos sindicalistas universitários aos modelos educacionais vigentes, mas, também reconhecer os vínculos políticos que nos impulsionam, estimulando, assim, as reflexões que tornem possíveis a convergência de seus propósitos políticos e sociais. 
ABSTRACT: This article is a part of a wider research, the aim of which is to discuss the history and political clashes of professors' unionism in Latin America. Thus, this paper focuses on some aspects of the professors union organization in Brazil and takes as its focus the entities linked to the São Paulo state universities, seeking to understand the role of those unions and associations from a socio-historical perspective. It is also proposed the analysis of the political clashes and agency with educators in the years 1990-2010, a period marked by government policies for reform of the State in general and of the university in particular. Therefore, this research is placed in the field of critical social history of education, trying to contribute to the production of knowledge revealing the actions, struggles and questions presented by university unionists to effective educational models, thus stimulating the reflections that make possible the convergence of their political and social purposes.

KEY WORDS: Associativism. Teacher trade unionism. Workers in education.

\section{REFERÊNCIAS}

ADUNICAMP. Associação dos Docentes da Universidade de Campinas. História. Campinas: Universidade de Campinas, 1977. Disponível em:

<http://www.adunicamp.org.br/Entidade/Historia/Default.aspx>. Acesso em: 30 abr. 2012.

ADUSP. Associação dos Docentes da Universidade de São Paulo. Histórico da ADUSP. São Paulo: Universidade de São Paulo, [19--]. Disponível em: <http://www.adusp.org.br/index.php/a-adusp2/historico>. Acesso em: 30 abr. 2012.

ALMEIDA, D. M.; FERREIRA JUNIOR, A. As pesquisas sobre o associativismo docente no Brasil: o que dizem as produções acadêmicas nacionais? In: BAUER, C. et al. (Org.). Sindicalismo e associativismo dos trabalhadores em educação no Brasil. Jundiaí: Paco Editorial, 2015. p.77-89.

ANDES. Associação Nacional dos Docentes do Ensino Superior. História. Brasília: ANDES Sindicato Nacional, [19--]. Disponível em:

<http://antigo.andes.org.br/historia.htm>. Acesso em: 02 mai. 2012,

CÂNDIDO, A. Palestra proferida em 1979. In: ADUSP. Associação dos Docentes da Universidade de São Paulo. Histórico da ADUSP. São Paulo: Universidade de São Paulo, [19--]. Disponível em: 〈http://www.adusp.org.br/index.php/a-adusp2/historico〉. Acesso em: 30 abr. 2012.

DAL ROSSO, S. Elementos para a teoria do sindicalismo no setor da educação. In: DAL ROSSO, S. (Org.) Associativismo e sindicalismo em educação. Organização e lutas. Brasília: Paralelo 15, 2011. p.17-27.

GENTILI, P. (Org). Universidades na penumbra: neoliberalismo e reestruturação universitária. São Paulo: Cortez, 2001. et al. Reforma educativa y luchas docentes en America Latina. Educação \& Sociedade, Campinas, v.25, p.1251-1274, 2004. 
GINDIN, J. Os estudos sobre sindicalismo docente na América Latina e no Brasil. In: SEMINÁRIO INTERNACIONAL PARA DISCUSSÕES DE PESQUISAS:

associações e sindicatos dos trabalhadores em educação, 2009, Rio de Janeiro. Anais... Rio de Janeiro: IUPERJ/UFRJ/UnB, 2009.

GOUVEIA, A. B.; FERRAZ, M. A. S. Sindicalismo docente e política educacional: tensões e composições de interesses corporativos e qualidade da educação. Educar em Revista, Curitiba, n.48, p.111-129, abr./jun. 2013.

MANCEBO, D. Trabalho docente na educação superior: problematizando a luta. In: DAL ROSSO, S. (Org.). Associativismo e sindicalismo em educação. Organização e Lutas. Brasília: Paralelo 15, 2011. p.69-88.

SADER, E. A nova toupeira. São Paulo: Boitempo, 2009.

VIANNA, C. Os nós do "nós": crise e perspectiva da ação coletiva docente em São Paulo. São Paulo: Xamã, 1999 